Conclusion In contrast to static information transfer, narrative techniques to reconstruct and reflect on recent encounters provide depth and relevance to counselling interactions, addressing multiple dimensions of HIV/STI risk experienced by MSM in Latin America.

\subsection{BEHAVIOURAL CHANGE TO REDUCE THE RISK OF PHARYNGEAL GONORRHOEA IN MEN WHO HAVE SEX WITH MEN}

Eric PF Chow, Sandra Walker, Tiffany Phillips, Christopher K Fairley. Melbourne Sexual Health Centre

\subsection{6/sextrans-2017-053264.11}

Introduction Gonorrhoea rate continues to increase at alarming rates among men who have sex with men (MSM), particularly in young MSM, in Australia and worldwide. A recent study has shown that use of antiseptic alcohol-containing mouthwash can inhibit the growth of gonorrhoea in the pharynx. The aim of this study was to examine the willingness of MSM to change their behaviours to reduce the risk of gonorrhoea.

Methods A cross-sectional questionnaire-based study was conducted among MSM attending the Melbourne Sexual Health Centre, Australia, between March and September 2015. Participants were asked how likely they would change their behaviours to reduce the risk of pharyngeal gonorrhoea. Six different strategies were asked: (1) stop tongue kissing with partners; (2) stop having receptive oral sex from partners (partner's penis in participant's mouth); (3) stop rimming partners (participant's tongue in or around partner's anus); (4) stop using saliva as lube for anal sex; (5) use condoms for oral sex; and (6) use alcohol-containing mouthwash daily.

Results A total of 926 MSM were surveyed with a median age of 29 (IQR 25-36) years. The majority of MSM $(65 \%$ [95\% CI 62\%-69\%]) expressed they were likely to use mouthwash daily to reduce the risk of pharyngeal gonorrhoea, followed by stop using saliva as lube $(63 \%$ [95\% CI $60 \%-$ 66\%]), and stop performing rimming (49\% [95\% CI 46\%$53 \%])$. In contrast, the majority of MSM (78\% [95\% CI $75 \%-80 \%])$ expressed they were unlikely to stop kissing to reduce the risk of pharyngeal gonorrhoea. Young MSM were more likely to use mouthwash daily to reduce the risk of gonorrhoea compared to older MSM.

Conclusion Men are less likely to change their sexual practices to reduce the risk of pharyngeal gonorrhoea however they are likely to use mouthwash daily to reduce the risk, particularly younger MSM.

\section{Oral Presentation Session 3}

\section{STI Prevention/Diagnosis and Community Engagement}

\subsection{AIDS PREVENTION POLICY AT SCHOOL IN BRAZIL (1994-2014) AND THE ROLE OF UNESCO}

${ }^{1}$ Luis Carlos Romero, 1,2Mariana Braga Neves, 'Maria Arebeca Otero Gomes. 'UNESCO; ${ }^{2}$ SBRASH

10.1136/sextrans-2017-053264.12
Introduction Information, values and knowledge transmitted by the school influence the lives of adolescents and young people. The school congregates a considerable proportion of this population, facilitating access to it. The objective was to analyse the evolution of the AIDS prevention policy for adolescents and young people developed in schools and the role of Unesco.

Method Documentary analysis and interviews. Interviews with health and education managers, CSOs/NGOs and stakeholders to confirm, qualify and complement information produced by documentary analysis.

Results National policy formulated in 1994: School Project (1995-2004); Health and Prevention in School Project (SPE) (2005-2007); Health in School Program (PSE) (2007-2014). Initially with a focus on prevention, the actions passed to integrate a broad set of objectives and contents of health, educational-preventive and care. Large number of schools work the themes; Low effectiveness of educational action. Availability of condoms in schools is little implemented.In the political environment, there is a resurgence of positions that are contrary to discuss sexual diversity at school with a reflection on the activities, mainly considering the interference of conservative political parties and the lobbying of Catholic and Evangelical churches with the decision-making bodies of politics and the management.

Conclusion Young people remain as one of the key populations to control the epidemic. Future of STI and AIDS prevention in litigation schools: Most managers and stakeholders believe that action should be rethought and taken up in isolation or associated with complementary strategies; Others argue that it must be replaced, because it has failed and because the school has become a barrier to young people. UNESCO had a strategic and essential role to promote the approximation of interests and articulation and cooperation between the Ministries of Health and Education.

\subsection{UNDERSTANDING SEXUAL HEALTH LANGUAGE: COMMUNITY ENGAGEMENT WITH REFUGEES FROM BURMA, POST SETTLEMENT IN AUSTRALIA}

${ }^{1}$ Amita Tuteja, ${ }^{2}$ Lena Sanci, ${ }^{3}$ Lester Mascarenhas, ${ }^{4}$ Elisha Riggs, ${ }^{3}$ Lynette 0 Dwyer, ${ }^{3}$ Di Van Villet, ${ }^{3}$ Katrina Sangster, ${ }^{3}$ Kim Mcguiness, ${ }^{2}$ Meredith Temple-Smith. ${ }^{1}$ Department of General Practice, University of Melbourne, Melbourne, Australia; ${ }^{2}$ Department of General Practice, University of Melbourne, Melbourne, Australia; ${ }^{3}$ Isis Primary Care, Hoppers Crossing, Melbourne, Australia; ${ }^{4}$ Murdoch's Children Research Institute, Royal Children's Hospital, University of Melbourne, Melbourne, Australia

\subsection{6/sextrans-2017-053264.13}

Introduction Heath care professionals (HCP) who use interpreters in reproductive health consultations with people of dissimilar cultural backgrounds often describe situations where interpreters and patients who speak the same language fail to convey intended meanings. Interpreters struggle to explain certain words, attempt to substitute taboo words or explain terms with paragraphs. This study aims to engage with refugees from Burma to critically examine the language and vocabulary of sexual health consults.

Methods Using qualitative techniques, we interviewed $27 \mathrm{HCP}$ (doctors, nurses, interpreters, social workers) involved with refugees from Burma. The interview guide drew from a conceptual framework based on principles of "humanization" of reproductive health care interlinked with ideas of "sustainable development". Interviews were audio-recorded and transcribed. 
Research team members reached consensus on coding, content and thematic analysis and key results.

Results Preliminary analysis yielded four themes including a) limited reproductive health vocabulary in some ethnic dialects from Burma b) use of euphemisms to increase cultural acceptance of reproductive health terms c) low levels of health literacy and frequent improvising with similes and metaphors for simplification d) deviation of interpreters from conduit roles to practitioner aids for smooth communication. For instance, the word for intercourse in Chin language is "hupa sual nak" with the literal meaning of "man and woman commit sin". Discussion of sexual intercourse thus requires skillful interpretation.

Conclusion A close look at sexual constructs in an unfamiliar language highlights the imaginative resources used by interpreters to assist HCP in understanding patients' inner world. A real challenge is for the HCP to recognise the meaning when the words used mean something similar to both patient and interpreter but the verbatim translation loses accuracy. Awareness of nuances of sexual health vocabulary will create smooth sexual health dialogue, and generate greater rapport with the patient.

\subsection{SEX INDUSTRY REGULATION, SEX WORKER HEALTH AND STI/HIV PREVENTION}

Victoria Powell, Eva Karlsen. Scarlet Alliance, Australian Sex Workers Association

\subsection{6/sextrans-2017-053264.14}

Introduction The ability of sex workers to access healthcare and STI/HIV prevention education and tools is directly impacted by policy and law. Australia provides a unique case study of the direct effects of criminalisation, licensing, and decriminalisation on access to healthcare and rates of STI/HIV transmission as each state and territory has differing models of regulation operating side by side. New South Wales decriminalised sex work in 1995 in response to government findings of systemic police corruption; criminal laws repealed and police no longer regulators, sex work is regulated through standard occupational, planning and industrial mechanisms.

Methods Scarlet Alliance, the peak national sex work organisation, collects data directly from sex workers via forums, working groups and surveys. We conducted an in-depth, five stage consultation with sex workers from a range of genders, experiences and backgrounds. We reviewed health research and government reports to examine policy successes and areas in need of reform.

Results Under decriminalisation NSW sex workers have better access to healthcare and STI/HIV education and prevention tools including free, confidential and anonymous sexual health services as well as peer-led services. Higher rates of safer sex, lower rates of STIs and improved Workplace Health and Safety were also evident, while in other jurisdictions sex workers continue to face barriers to treatment and other health services and often work outside legal frameworks.

Conclusion Decriminalisation is the optimal regulatory model and is supported by the UNFPA, UNDP, UNAIDS, WHO and Amnesty International as critical to HIV prevention and for human rights. Despite 22 years of evidence of its success, barriers remain to the uptake of this model in Australia and globally including political pressure to criminalise clients, hostile funding environments, the booming "rescue industry and institutional discrimination. The Australian case study supplies valuable evidence for governments, researchers, the health sector and the global sex work community.

\subsection{THE ROLE OF SOCIAL SCIENCE AND PUBLIC PATIENT INVOLVEMENT IN THE DEVELOPMENT OF NOVEL RAPID DIAGNOSTIC TESTS FOR STIS AND ANTIMICROBIAL RESISTANCE DETECTION}

Agata Pacho, Claire Broad, Emma Harding-Esch, Syed Tariq Sadiq, Sebastian S Fuller. St George's, University of London

\subsection{6/sextrans-2017-053264.15}

Introduction Patient and Public Involvement (PPI) is increasingly seen as necessary for conduct of high-impact ethical research, but when focused on short-term treatable sexually transmitted infections (STIs) it can be challenging to gain participants. The Precise Study is a collaboration to develop and evaluate point of care tests (POCTs) for short-term STI infection and Antimicrobial Resistance (AMR) detection. We explored patient opinions concurrent to POCT development, through qualitative interviews and PPI activities.

Methods Qualitative 1-on-1 interviews were conducted with a purposive sample of patients in three sexual health clinics (SHCs) in England. PPI activities included development of a patient and public advisory group (PAG). Interview topics were presented for discussion at one PAG meeting. Members were unaware of qualitative interview results until after they gave their opinions. Findings from qualitative interviews were compared with PAG meeting notes to better understand results of the two approaches.

Results 31 patient interviews were conducted in SHCs: 11 women, 12 heterosexual men and 8 men who have sex with men. Most patients felt POCTs were preferable to standard care, and many suggested ways to implement the tests in new clinical pathways. Our PAG had 4 members of the public: 3 women and 1 man, all with previous experience in healthcare settings. PAG member opinions of the POCTs and importance of the AMR test mirrored key themes found in patient interviews, however, PAG members focused on the potential for advocacy that POCTs provide, and suggested publicising rapid turnaround of results to encourage testing in high-risk groups with low clinic attendance.

Conclusion We have demonstrated that PPI is possible for stigmatised, treatable short-term STIs, provides new insights into care and utility and allows for continued dialogue on implementing solutions to meet patient concerns. We suggest that where possible, qualitative research is used to iterate the diversity of patient opinions, and is complemented by PPI to build patient-centred solutions.

\subsection{ISEAN-HIVOS PHILIPPINES: STRENGTHENING CAPACITIES OF COMMUNITY-BASED ORGANISATIONS (CBO) THROUGH ORGANISATIONAL DEVELOPMENT (OD) FOR SUSTAINABILITY OF COMMUNITY-LED HIV AND RIGHTS-BASED INTERVENTIONS}

RN Cortes. The Philippine NGO Council on Population, Health And Welfare, INC 